\title{
PERENCANAAN STRATEGIS SISTEM INFORMASI MENGGUNAKAN IT BALANCE SCORECARD DI KAMPUS AMIK AKMI BATURAJA
}

\author{
Dian Sri Agustina ${ }^{1}$, Yunita Trimarsiah² \\ ${ }^{1,2}$ Jurusan Teknik Informatika AMIK AKMI Baturaja \\ e-mail: dian.sriagustina@gmail.com¹, yunitatrimarsiah@yahoo.co.id²
}

\begin{abstract}
Nowadays, the Strategic planning information system was one of the keys in achieving an organization, one of them was at campus of AMIK AKMI Baturaja, where the development of information technology could help to improve the quality and service to the students so that they could produce the quality that was ready to compete. Therefore, this research had the aim to create the strategic planning of information system to increase the performance of Job. The Strategic Planning Model of Information system that would be discussed in this case was by using IT Method of Balance Scorecard. The result of research showed a strategic planning model of information system, which mapped into four BSC IT perspective, they were the orientation of the user's perspective, the contribution of the company, the operational improvement, and the future orientation. To clarify the results of the analysis used tools: SWOT and MC Farlan's. The results of strategic planning were in the form of framework and the future application portfolio. To measure and examine the strategic planning was created, used a SI performance measure, namely IT Balanced Scorecard (BSC). Strategic planning was expected to be the best answer to the problems faced.
\end{abstract}

Keywords: Information system, IT Balance Scorecard Method, Strategic planning

\section{INTISARI}

Perencanaan strategis sistem informasi kini merupakan salah satu kunci dalam pencapaian sasaran suatu organisasi, salah satunya di kampus AMIK AKMI Baturaja dimana perkembangan teknologi informasi dapat membantu meningkatkan mutu dan pelayanan terhadap mahasiswa sehingga dapat menghasilkan kualitas yang siap bersaing. Dimana pemanfaatan Teknologi Informasi di AMIK AKMI belum optimal, dilihat dari semua kegiatan belum terintegrasi secara keseluruhan dan setiap unit bagian belum memiliki Sistem Informas. Oleh karena itu, Penelitian ini bertujuan untuk membuat perencanaan strategis sistem informasi untuk meningkatkan kinerja. Model perencanaan strategis sistem informasi yang akan dibahas dalam kajian ini adalah menggunakan metode IT Balance Scorecard. Hasil kajian menunjukkan sebuah model perencanaan strategi sistem informasi, yang dipetakan ke dalam 4 perspektif IT BSC, yaitu persepektif user orientasi, kontribusi perusahaan, penyempurnaan operasional, orientasi masa depan. Untuk memperjelas hasil analisis digunakan tools : SWOT dan MC Farlan's. Hasil perencanaan strategis ini dalam bentuk framework dan portofolio aplikasi mendatang. Untuk mengukur dan menguji rencana strategis yang dibuat, digunakan sebuah alat ukur kinerja SI yaitu IT Balance Scorecard (BSC). Perencanaan strategis ini diharapkan dapat menjadi jawaban terbaik atas permasalahan yang dihadapi.

Kata Kunci : Metode IT Balance Scorecard, Perencanaan strategis, Sistem informasi

\section{PENDAHULUAN}

Dewasa ini tidak dapat dipungkiri bahwa informasi menjadi salah satu sumber daya utama pada suatu organisasi untuk meningkatkan daya saing terhadap para pesaingnya salah satunya di dalam sektor pendidikan. Oleh karena itu setiap organisasi mencoba untuk menerapkan sistem atau teknologi informasi agar dapat meningkatkan efesiensi dan efektifitas dalam proses bisnis, juga agar mampu memberikan nilai tambah yaitu berupa competiteve advantage dalam persaingan bisnis[1].

Kampus AMIK "AKMI" Baturaja masih memiliki banyak kekurangan dalam hal pemanfaatan Teknologi Informasi, hal tersebut dapat dilihat dari semua kegiatan yang dilakukan belum terintegrasi secara keseluruhan. Dan di setiap unit bagian belum semua memiliki sistem informasi untuk mendukung kelengkapan data di AMIK “AKMI" Baturaja, sehingga data dan informasi yang diperlukan tidak lengkap . 
Untuk menerapkan Sistem Informasi secara efektif di kampus AMIK AKMI Baturaja, dibutuhkan perencanaan strategis sistem informasi. Perencanaan strategis ini digunakan untuk mengembangkan Sistem Informasi yang sudah ada agar lebih optimal dan terintegrasi, berarti merencanakan sistem informasi yang saling berkaitan sesuai dengan fungsi dan proses bisnis suatu organisasi dengan tujuan menghasilkan suatu sistem informasi yang efisien dan tepat sasaran dalam tujuan mencapai kinerja yang lebih baik.

\section{DASAR TEORI}

\section{A. Perencanaan Strategis SI/TI}

Perencanaan adalah suatu proses yang melibatkan penentuan sasaran atau tujuan organisasi, menyusun strategi menyeluruh untuk mencapai sasaran yang ditetapkan dan mengembangkan hirarki rencana secara menyeluruh untuk mengintegrasikan dan mengkoordinasikan kegiatan.

Strategi dapat didefinisikan sebagai suatu rangkaian tindakan - tindakan terpadu yang menjadi alat untuk meningkatkan keberhasilan dan kekuatan jangka panjang sebuah perusahaan dalam mencapai keunggulan bersaing[2].

Sistem informasi adalah kombinasi sumber daya yang terorganisir dsri manusia, perangkat keras, piranti lunak, jaringan komputer dan data yang mengumpulkan, mengubah dan mendistribusikan informasi pada suatu organisasi[3].

\section{B. IT Balanced Scorecard}

Pada tahun 1997, Van Grembergen dan Van Bruggen mengadopsi Balanced Scorecard (BSC) untuk digunakan pada Departemen Teknologi Informasi organisasi. Dalam pandangan mereka karena Departemen Teknologi Informasi merupakan penyedia layanan internal maka perspektif yang digunakan harus diubah dan disesuaikan. Dengan melihat bahwa pengguna mereka adalah pegawai internal dan kontribusi mereka dinilai berdasarkan pandangan pihak manajemen maka mereka mengajukan perubahan seperti pada Gambar 2 [4].

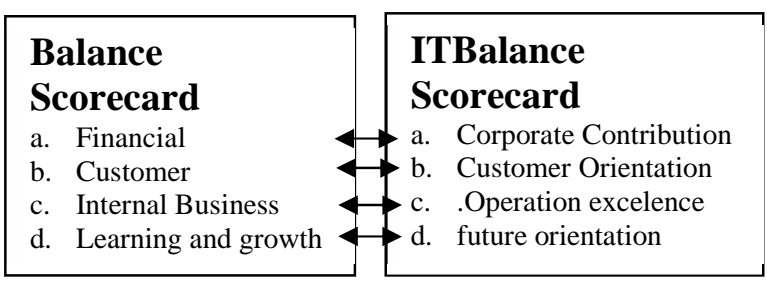

Gambar 1. Perubahan perspektif BSC Tradisional menjadi IT Balanced Scorecard

(Sumber: Grembergen, 2001)

Beberapa tujuan organisasi dalam mengimplementasikan framework IT Balanced scorecard yang diimplementasikan secara luas, diantaranya untuk:

1. Menyelaraskan perencanaan TI dengan tujuan bisnis dan kebutuhan bisnis.

2. Membangun pengukuran yang tepat dalam evaluasi efektivitas TI.

3. Menyelaraskan/menyetarakan usaha-usaha karyawan untuk mencapai sasaran-sasaran TI.

Meningkatkan kinerja teknologi informasi. Memberikan atau mendapatkan hasil yang seimbang bagi kepentingan seluruh stakeholder[5].

\section{METODE PENELITIAN}

\section{A. Tempat Penelitian}

Tempat penelitian dilakukan pada Kampus AMIK “AKMI" Baturaja yang beralamatkan di Jl. Jendral. A. Yani no 267A Tanjung Baru, Baturaja Timur Ogan Komering Ulu ruang lingkup penelitian meliputi sistem informasi pada unit bagian.

\section{B. Kerangka Penelitian}

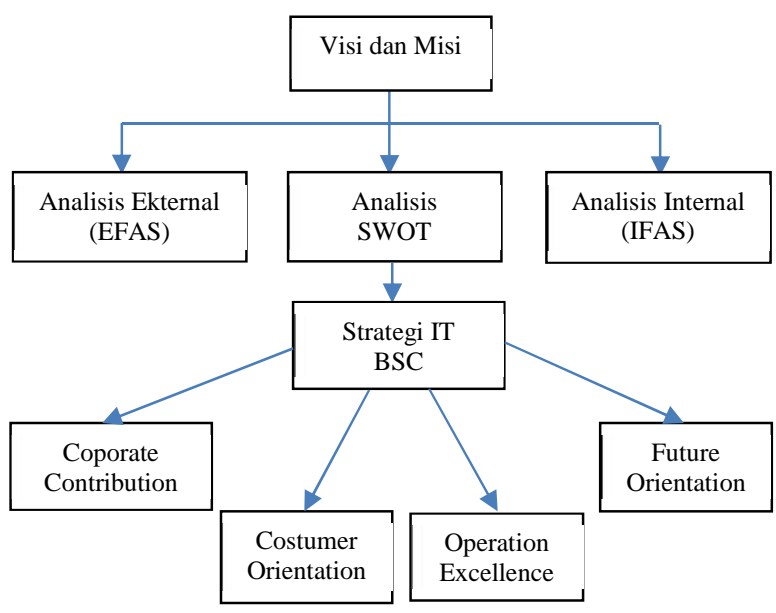

Gambar 2. Kerangka penelitian 


\section{Metode Pengumpulan Data}

Dalam pengumpulan data untuk penelitian ini digunakan beberapa cara yaitu:

\section{Observasi}

Observasi adalah teknik pengumpulan data melalui pengamatan secara langsung pada objek penelitian, yaitu di AMIK AKMI Baturaja. Teknik ini merupakan teknik pengumpulan data yang efektif untuk mempelajari suatu sistem. Dengan teknik ini maka data yang didapat mempunyai nilai yang tinggi, karena penulis secara langsung melihat apa yang sedang dikerjakan.

2. Wawancara

Dalam penelitian ini peneliti menggunakan Metode wawancara digunakan untuk memperoleh keterangan tentang kejadian yang oleh peneliti tidak dapat diamati sendiri secara langsung. Operasionalisasinya dilakukan dengan mengadakan wawancara secara mendalam kepada berbagai informan lain sehubungan dengan pokok masalah yang akan diteliti. Metode wawancara digunakan dengan para user (pemakai) yang akan menggunakan Sistem ini.

\section{Metode Kuisioner}

Pada metode ini kegiatan yang dilakukan adalah membuat beberapa pertanyaan untuk mengetahui keinginan user dalam kemudahan penggunaan sebuah sistem dan mendapatkan informasi.

4. Metode Studi Pustaka

Studi pustaka, mempelajari mencari dan mengumpulkan data yang berhubungan dengan penelitian seperti buku, internet, yang berkaitan tentang perencanaan strategis menggunakan IT Balance Scorecard.

\section{Analisis IT Balance Scorecard}

IT BSC dapat menjabarkan dan memproyeksikan dalam memberikan kerangka berpikir untuk menjabarkan strategi penerapan IT perusahaan ke dalam empat perspektif IT. Untuk memanfaatkan IT BSC sebagai instrumen keselarasan manajemen, harus meningkatkan hubungan sebab-akibat antara measures dari setiap perspektif IT BSC. Hubungan ini diartikulasikan oleh dua jenis metrik yaitu outcome measure dan performance drivers [6]. Seperti ditunjukkan dalam Gambar 3, tiga perspektif lainnya memiliki hubungan sebab akibat yang pada akhirnya akan mempengaruhi corporate contribution.

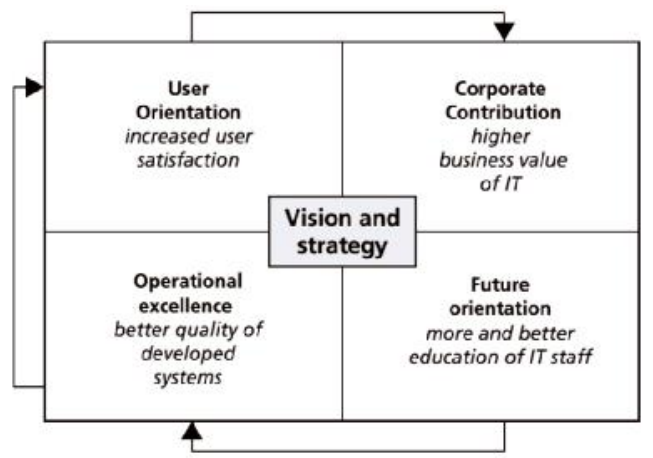

Gambar 3. Hubungan sebab akibat IT BSC

\section{HASIL DAN PEMBAHASAN}

\section{A. Gambaran Umum Responden}

Responden yang akan dijadikan sampel yaitu pimpinan, staf dan dosen AMIK AKMI Baturaja. Berdasarkan hasil tabulasi data penelitian yang dilakukan terhadap 60 responden dapat dikemukakan identitas responden berdasarkan pengguna seperti berikut:

1. Direktur

2. Pudir 1

3. Pudir 2

4. Pudir 3

5. Ka. Prodi

6. Kabag.

7. Staf

8. Dosen

Karakteristik responden berdasarkan jenis kelamin seperti yang tampak pada Tabel 1 yaitu :

Tabel 1. Komposisi Jenis Kelamin

\begin{tabular}{|c|l|c|}
\hline No & Pengguna & Jumlah \\
\hline 1 & Laki-laki & 20 \\
\hline 2 & Perempuan & 40 \\
\hline \multicolumn{2}{r|}{ Total } & 60 \\
\hline
\end{tabular}

Karakteristik responden berdasarkan tingkat pendidikan dapat dilihat pada Tabel 2 sebagai berikut : 
Tabel 2. Komposisi Tingkat Pendidikan

\begin{tabular}{|c|l|c|}
\hline No & $\begin{array}{c}\text { Tingkat Pendidikan } \\
\text { (Ijasah Terakhir) }\end{array}$ & Jumlah \\
\hline 1. & SLTA & 6 \\
\hline 2. & D3 & 13 \\
\hline 3. & S1 & 9 \\
\hline 4. & S2 & 32 \\
\hline \multicolumn{2}{|c|}{ Total } \\
\hline
\end{tabular}

\section{B. Peta Strategi AMIK AKMI Baturaja}

Dari penilaian bobot terhadap setiap perspektif IT Balanced Scorecard pada AMIK AKMI, dapat dikelompokkan strategi TI kedalam 4 perspektif IT Balanced Scorecard menggunakan pola hubungan sebab akibat pada Tabel 3 berikut:

Tabel 3. Hubungan Sebab Akibat TI

\begin{tabular}{|l|l|}
\hline \multicolumn{1}{|c|}{ Perspektif } & \multicolumn{1}{|c|}{ Tujuan } \\
\hline $\begin{array}{l}\text { Penyempurnaan } \\
\text { Operasional } \\
\text { (Operational } \\
\text { Excellence) }\end{array}$ & $\begin{array}{l}\text { Penerapan sistem } \\
\text { informasi yang } \\
\text { terintegrasi }\end{array}$ \\
\hline $\begin{array}{l}\text { Orientasi Masa } \\
\text { Depan } \\
\text { (Future } \\
\text { Orientation) }\end{array}$ & $\begin{array}{l}\text { Meningkatkan mutu } \\
\text { dan kompetensi TI } \\
\text { SDM }\end{array}$ \\
\hline $\begin{array}{l}\text { Kontribusi } \\
\text { Perusahaan } \\
\text { (Corporate } \\
\text { Contribution) }\end{array}$ & $\begin{array}{l}\text { Evaluasi dan } \\
\text { mengembangkan } \\
\text { sistem TI }\end{array}$ \\
\hline $\begin{array}{l}\text { Orientasi } \\
\text { Pengguna } \\
\text { (User Orientation) }\end{array}$ & $\begin{array}{l}\text { Meningkatkan } \\
\text { kualitas layanan } \\
\text { berbasis TI }\end{array}$ \\
\hline
\end{tabular}

Dari hasil analisis sebab akibat di atas Tabel 3 dapat dikelompokkan dan disusun strategi TI AMIK AKMI ke dalam 4 (empat) perspektif $I T$ Balanced Scorecard dalam bentuk peta strategi TI Gambar 4. sebagai berikut:

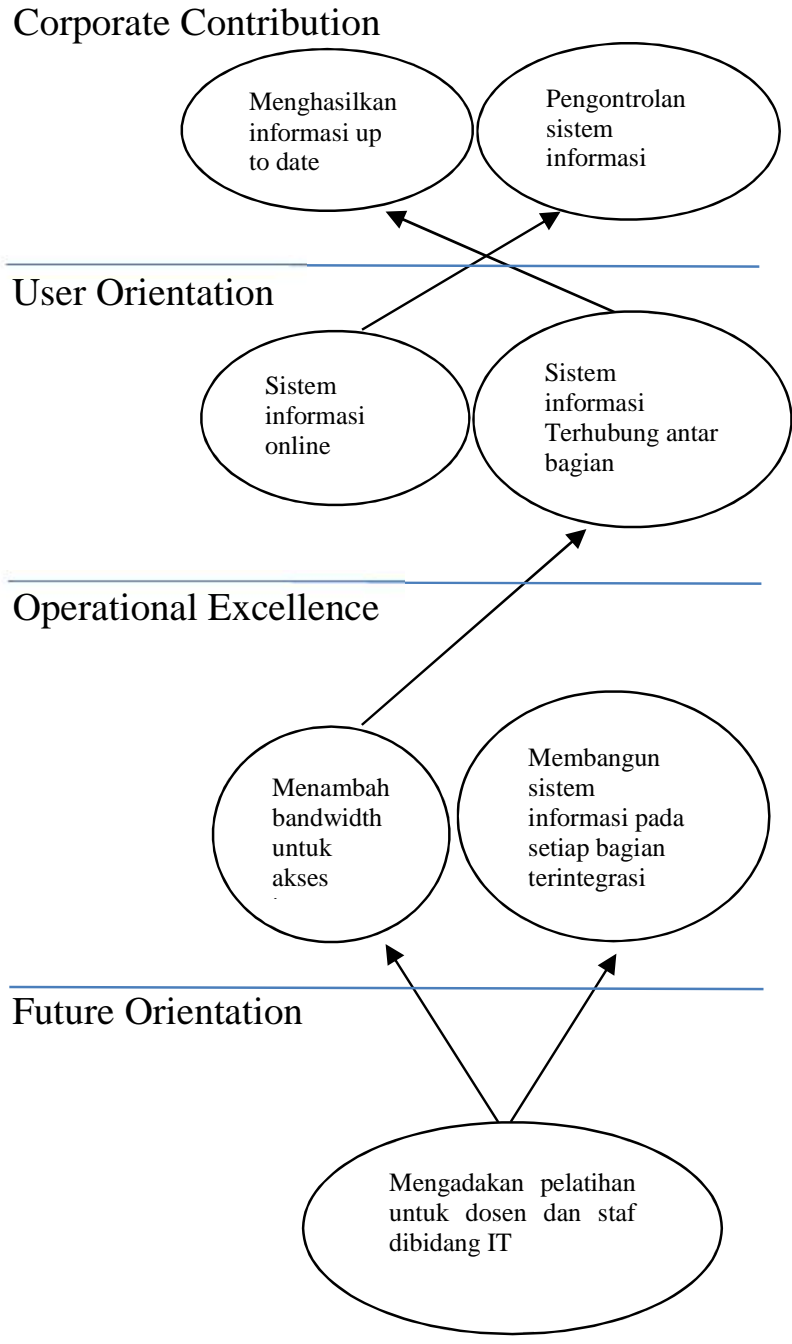

Gambar 4. Peta Strategi IT

\section{KESIMPULAN}

Berdasarkan hasil penelitian dan analisis yang telah dilakukan pada bab - bab sebelumnya, maka dapat diambil kesimpulan diantaranya :

1. Hasil dari Perencanaan strategi sistem informsi ini memiliki pengaruh positif terhadap kinerja perguruan tinggi AMIK AKMI pada seluruh aspek .

2. Dari analisis SWOT menghasilkan faktor internal yaitu kekuatan (strength) dan kelemahan (weakness) dan faktor eksternal yaitu peluang (Opportunity) dan ancaman (threats). Di mana setiap faktor di lakukan pembobotan sehingga dapat diketahui faktor mana yang berperan besar dalam meningkatkan kinerja sistem. 
Perencanaan strategis sistem informasi AMIK AKMI menggunakan metode IT Balance Scorecard menghasilkan data dari 4 perspektif yaitu Kontribusi Perusahaan (Corporate Contribution),perspektif Orientasi Pengguna (User Orientation), perspektif Penyempurnaan Operasional (Operational Excellence), dan perspektif Orientasi Masa Depan (Future Orientation) sehingga menghasilkan suatu konsep untuk membangun atau mengembangkan Sistem Informasi yang menghasilkan framework dan Portofolio (McFarlan).

\section{SARAN}

Untuk Meningkatkan proses bisnis AMIK AKMI, penulis memberikan beberapa saran sebagai berikut :

1. AMIK AKMI harus meningkatkan kualitas SDM dari semua aspek seperti: dengan memberikan pelatihan-pelatihan dalam menggunakan dan mengelola sistem informasi.

2. Sistem Informasi yang sudah ada di kembangkan dan yang belum dibangun menjadi satu kesatuan atau terintegrasi

\section{DAFTAR PUSTAKA}

[1] Wijaya, R. (2007). Analisis model IT menggunakan Balance Scorecard untuk Pengembangan Sistem Teknologi. Jurnal Sistem Informasi, Universitas Kristen Maranatha. Vol. 2 No. 1

[2] Ward, J. and Peppard, J. (2002). Strategic Planning For Information System 3rd ed., John Wiley \& Sons, inc. NY.

[3] O'Brien, J. (2005). Pengenalan Sistem Informasi. Salemba Empat. Jakarta

[4] Van Grembergen, W. and Haes, S.D. (2005). Measuring and Improving Coporate InformationTecnology through the Balance Scorecard. Information System Control Journal. Vol. 2.

[5] Keyes, J. (2005). Implementing The IT Balanced Scorecard. Auerbach Publication

[6] Van Grembergen, W. (2000). The Balanced and IT Governance. Information Systems Control Journal, 40-41 